\title{
Embedding animal welfare in sustainability assessment: an indicator approach
}

M. Brennan ${ }^{1,2 \dagger}$, T. Hennessy ${ }^{1}$, E. Dillon ${ }^{2}$

${ }^{1}$ CUBS UCC, Cork University Business School, University College Cork, Cork, Ireland

${ }^{2}$ Rural Economy Development Programme, Teagasc, Athenry, Co. Galway, Ireland

Abstract

In line with growing consumer interest in sustainable food production, a number of farm-level sustainability indicator studies have been published in recent years. Despite the importance of animal welfare, many such frameworks fail to adequately take account of it, mostly due to difficulties in accessing suitable data. This paper demonstrates that it is possible to develop indicators of animal welfare that can be embedded within a wider sustainability framework using a representative farm-level dataset such as the European Union (EU) Farm Accountancy Data Network (FADN) for Ireland, the Teagasc National Farm Survey. The paper presents a set of sustainability indicators for dairy farms in Ireland for the 2014-2017 period and examines the impact of policy reform on sustainability performance. Headline results show that welfare standards on dairy farms in Ireland have remained stable over the period despite the considerable intensification of the dairy sector following EU milk quota removal. Furthermore, dairy farms that have expanded herd size significantly have improved welfare standards more than farms that have not increased production. An analysis of synergies and trade-offs between the various aspects of sustainability reveals that positive correlations exist between welfare standards and economic and environmental performance. The analysis facilitates the identification of win-win farm-level strategies that can be adopted to improve economic, environmental and animal welfare outcomes. The framework developed here presents opportunities for evaluating policy impacts at the farm level on various aspects of sustainability. The use of the FADN demonstrates the capacity to extend such an approach across the EU.

Keywords

Agricultural sustainability $\cdot$ composite welfare indicator $\bullet$ dairy cow welfare $\bullet$ dairy farm expansion $\bullet$ social sustainability

\section{Introduction}

The concept of sustainability is at the core of contemporary food and agricultural policy. The goal of the European Union (EU) Common Agricultural Policy (CAP), to continue to foster sustainable food production, is clearly reflected in the recent Green Deal and Farm to Fork strategies, which aim to make food systems fair, healthy and environmentally friendly. Indeed, the latter highlights the importance of the evaluation and revision of existing animal welfare legislation, and the further collection of data to assess the sustainability of farming more broadly. In line with legislation, there is a growing demand for practical and scientifically valid assessments of animal welfare in order to safeguard and address gaps, while satisfying the public's request for increased transparency. Indeed, over $80 \%$ of European citizens have cited animal welfare as a serious concern, believing that the welfare of farm animals should be better protected (European Commission, 2016).
Arising from market and political interests, a plethora of indicator-based assessments of the sustainability of food production have emerged (FAO, 2014; Van Asselt et al., 2014; Ryan et al., 2016; Bonisoli et al., 2019; Soldi et al., 2019). Although such studies typically include indicators of the economic, environmental and social performance of farms and/or food production, animal welfare is often inadequately addressed, as highlighted in a recent review by Brennan et al. (2020). Those studies that did address animal welfare utilised combinations of various resources and animalbased measures and tended not to be based on nationally representative datasets (Van Calker et al., 2005; Arandia et al., 2011; Lillywhite et al., 2012).

Traditionally, farm animal welfare has been assessed using resource-based measures reflecting welfare standards through management or environmental attributes, such as access to 
water or housing conditions (Battini et al., 2014; Phythian et al., 2019). More recently, animal-based measures, which have the ability to directly measure the welfare status of livestock, have been recognised as a more effective method (Phythian et al., 2019). One of the prominent welfare assessment methodologies to adopt the animal-based approach was the Welfare Quality (WQ) protocol (de Graaf et al., 2017). The WQ protocol outlined four main welfare principles: good feeding, good housing, good health and appropriate behaviour, with associated criteria and animal-based metrics by which to assess them, such as somatic cell count (SCC), mortality rate and body condition score (Blokhuis et al., 2010). These four principles have similar objectives to the "Five Freedoms" (FAWC, 2009) and are predominately measured at animal level, and thus are considered a useful guide for the measurement of animal welfare (EFSA, 2012). However, as the collection of such animal-based data is not feasible on a large, nationally representative scale, the utilisation of routinely collected data to assess the quality of herd management and animal welfare on farms has also been explored as a more practical alternative (Nyman et al., 2011; Warner et al., 2020). De Vries et al. (2011) identified numerous variables of routine herd data (VRHD), categorised across management, milk production and milk composition categories, and compared these with established welfare indicators (WIs), to identify associations between the two assessments. The VRHD included variables such as milk yield, SCC, fat, protein, mortality, access to pasture and housing systems. De Vries et al. (2011) concluded that many routinely collected herd variables had value in estimating dairy cow welfare. De Vries et al. (2014) reported that for most WIs, routinely collected herd data can operate as a pre-screening tool for the detection of dairy herds with severe welfare problems. This was further supported by Brouwer et al. (2015), who reported that routinely collected data, such as mortality rates and bulk tank SCC, displayed a significant association with animal-based measures such as the general health impression of the dairy cow, including rumen fill and body condition. Brouwer et al. (2015) concluded that an objective monitoring system, based on routinely collected data, served as a better diagnostic tool for detecting dairy herds with poor welfare health status than quarterly farm visits by the herd veterinary practitioners. However, ongoing challenges in defining and developing appropriate animal WIs from routinely collected data have contributed to the dearth of animal WIs in broader sustainability studies and variation in the legitimacy of different animal-based measures across welfare assessments (Winckler, 2019).

In the design of appropriate indicators, the multidimensional nature of sustainability and animal welfare is such that multiple variables using different scales may need to be assessed. To simplify interpretation, multidimensional indicators can be aggregated into a single indicator, termed a composite indicator (Cl) (Talukder et al., 2017). Intended to simplify complex information, Cls are now widely implemented within policy analyses and sustainability assessments, combining data on individual measures or indicators into a single index (Nardo et al., 2005). The WQ protocol utilised Cls to develop a welfare index, based upon numerous animal-based measures at the herd level (de Graaf et al., 2017), with a subsequent study developing a composite health indicator (De Vries et al., 2013). In their assessment of herd welfare, Warner et al. (2020) devised a Cl from routinely collected herd-level data from dairy farms in Canada.

The objective of this paper is to update an existing suite of farm-level sustainability indicators, developed using data from the Irish Farm Accountancy Data Network (FADN), to include a measure of animal welfare on Irish dairy farms, in order to test the relationship between welfare and other aspects of sustainability, and to record welfare changes through time. The analysis was conducted on data over a 4-yr period from 2014 to 2017 . This was a period of dramatic structural change in Irish dairy farms, in preparation for and during the aftermath of EU milk quota removal after three decades. Post-quota, milk production has increased by approximately $50 \%$ to date, with growth in both herd numbers and milk yield per cow across farms. The sector is therefore an interesting case study in which to explore herd management and assess animal welfare. While animal-based measures are not available through the dataset, existing herd-level data are instead used to identify suitable variables and develop a composite WI, which can act as a diagnostic tool for the detection of dairy herds with poor welfare status and can monitor progress during a period of intensification and expansion.

Previous sustainability assessments at the farm level in Ireland can be found in Dillon et al. (2016), Ryan et al. (2016) and Dillon et al. (2010), although animal welfare is not considered in these studies. This paper aims to fill that gap by investigating animal welfare and herd management on Irish dairy farms during a period of particular structural change, building on and complementing previous work. This approach facilitates an assessment of welfare and how it relates to wider sustainability metrics (economic, environmental and social). This paper addresses a number of research questions: (i) can expert-validated metrics of animal welfare be developed from a routinely collected, nationally representative dataset as part of a wider sustainability framework, (ii) how do measures of animal welfare relate to other indicators of agricultural sustainability and (iii) how does policy reform (i.e. abolition of milk quota) and subsequent production intensification impact the animal welfare standards. The following section of this paper describes the methodological approach used in the development of a $\mathrm{Cl}$ of animal welfare and the data utilised. There follows an overview of results and a general 
discussion of same, the limitations of the study are then discussed and final conclusions drawn.

\section{Materials and methods}

An adapted version of the Organisation for Economic Cooperation and Development (OECD, 2008) model for the development of sustainability indicators is used in this paper to identify appropriate variables and to develop a $\mathrm{Cl}$ of dairy cow welfare. The model for the development of such $\mathrm{Cls}$ is presented in Figure 1.

\section{Theoretical model}

The theoretical model to inform variable selection is drawn from Warner et al. (2020) and De Vries et al. (2011) who utilised routinely collected herd data, similar to the data available for this study, in their assessments of farm management and animal welfare. De Vries et al. (2011) identified three important dimensions of animal welfare: (i) production intensity, (ii) milk production and composition and (iii) management and facilities, and relevant variables were chosen to reflect these. Such data informed the selection of variables for our purposes. A brief overview is provided in the following paragraphs.

Herd mortality rate, in particular amongst younger animals, is one of the most pertinent methods to assess health status as it provides an insight into potential instances of diseases or insufficient animal husbandry (Ortiz-Pelaez et al., 2008; Seppä-Lassila et al., 2016). For our purposes, calf mortality is identified as the variable most appropriate to represent herd health. While calf mortality rates may be considered a coarse measure of welfare, in herd situations it can reveal the state of animal welfare at a group level (Seppä-Lassila et al., 2016). Common causes of calf deaths include gastrointestinal disorders, which account for $40 \%$ of deaths within the first 6 weeks, and pneumonia, which predominately impacts housed calves (Teagasc, 2017). In addition to their physical housing environment, dairy cow welfare and behaviour can be impacted by stocking rates (Wang et al., 2016). As such, stocking rate is also included as a variable important for the measurement of production intensity and is an interesting metric given the dramatic growth in Irish milk production in recent years.

Access to sufficient clean water and nutritious food is one of the most pertinent components of any animal welfare assessment. While animal-based indicators such as body condition score, conducted through a visual assessment, are optimal, they are not always feasible. As such, routinely collected variables can be used as proxies. Therefore, management-based metrics, such as total milk constituents, can be used to reflect herd nutrition which has a significant impact on milk composition and quality (Markert, 2017). Assessing fluctuations in milk constituents, namely fat and protein, can indirectly inform the farmer about potential metabolic health issues, such as sub-clinical ketosis (Jenkins et al., 2015; Hanuš et al., 2017). Moreover, low milk yields can result from an unbalanced diet, namely one which has low dry matter intake (Teagasc, 2016). The SCC of milk is also a leading indicator of intra-mammary infection as the leukocytes, which comprise the majority of somatic cell material, increase as an immune response to the presence of a mastitis-causing pathogen (Sharma et al., 2011). These variables are taken into consideration in our welfare assessment of Irish dairy herds.

The provision of sufficient animal shelter ensures protection in times of adverse weather conditions. Dry, well-bedded and draught-free housing are important factors for the health of dairy calves (Lorenz et al., 2011), particularly regarding their susceptibility to bovine respiratory disease, namely calf pneumonia (Earley et al., 2004). In Ireland, housing types consist of primarily slatted cubicle houses, followed by strawbedded sheds, with the former associated with superior health due to the ease of cleanliness afforded by the slatted system. Moreover, the age and quality of animal housing can

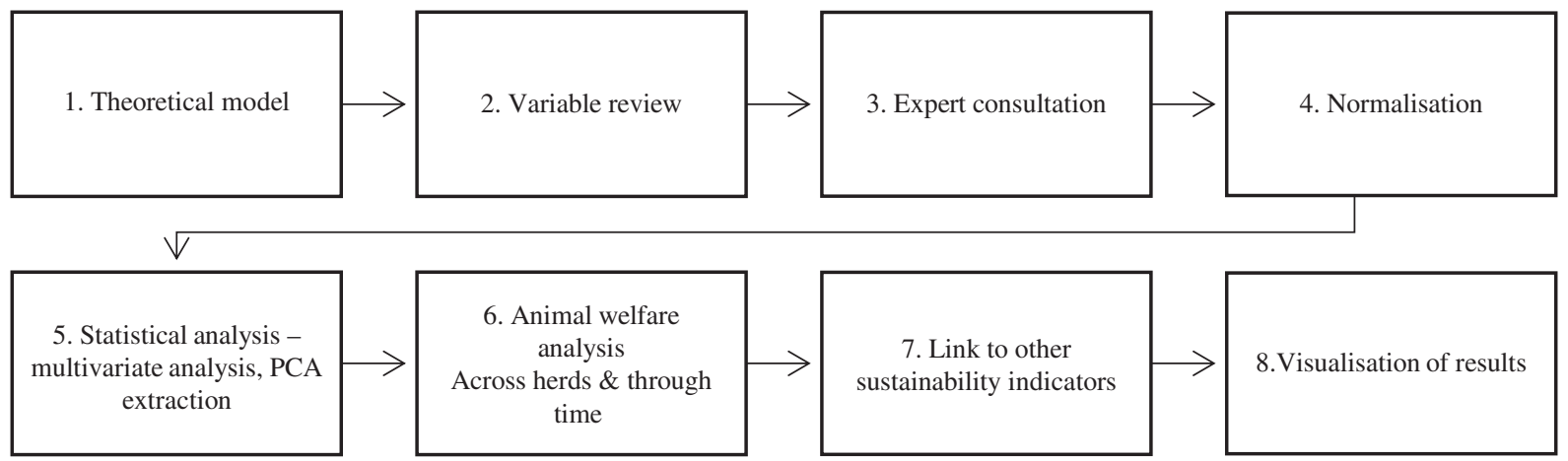

Figure 1. Methodological approach to the development of a composite welfare indicator. Source: Adapted from OECD (2008) PCA = principal component analysis. 
be indicative of the comfort level experienced by farm animals (Kelly et al., 2017). Analysing expenditure on dairy cow housing can be revealing of the level of modernisation of the system, and is of particular relevance considering the recent intensification of milk production in Ireland (Teagasc, 2019). The availability of space and the opportunity for animals to graze and express natural behaviours are also imperative for good welfare standards. Pasture-based cows have been shown to exhibit less agonistic behaviour than confined cows (Mee \& Boyle, 2020). In this paper, average days at grass is a key indicator of adequate herd management and animal welfare. Access to pasture may also alleviate hoof disorders and lead to less incidences of lameness compared to cattle in a housed system (Olmos et al., 2009). Furthermore, there are several health benefits associated with outdoor grazing: a reduction in observed cases of mastitis, lameness, hoof pathologies and mortality levels compared with cows on continuously housed systems (Arnott et al., 2017; Mee \& Boyle, 2020).

\section{Variable review}

The Teagasc National Farm Survey (NFS), part of the EU FADN, is the dataset employed to assess dairy cow welfare in this analysis. The survey collects detailed financial and production data from a nationally representative sample of approximately 900 Irish farms on an annual basis. Each farm is assigned a weighting factor to reflect the national farm population using weights from the Central Statistics Office. Primarily utilised to assess the financial situation on farms, the scope of the survey has been broadened over time, to collect data additional to that required in FADN, to develop a sustainability framework encompassing indicators of economic, environmental, social and innovation sustainability (Ryan et al., 2016). Economic indicators available through the survey include the economic return to land, productivity of labour, market orientation and economic viability. The environmental indicators include greenhouse gas (GHG) emissions, nitrogen and phosphorus use, and social indicators include agricultural education of the farmer, the demography of the household, isolation risk and work-life balance. A detailed description of the approach is available most recently in Buckley et al. (2019). Due to the constraints of the dataset, the scope of the indicators is limited to the herd level. In line with the approach utilised by Warner et al. (2020) and De Vries et al. (2011) to assess herd welfare status, the following eight variables were proposed for the indicator development: (i) stocking rate, (ii) dairy calf mortality, (iii) fatto-protein ratio, (iv) SCC, (v) milk yield, (vi) days at grass, (vii) building investment and (viii) housing type.

\section{Expert consultation}

The proposed variables were reviewed by five animal welfare experts employed across Irish and international research institutes. Experts were asked to evaluate the proposed variables in terms of their suitability to effectively represent dairy cow welfare, and secondly, to propose additional or alternative variables that are available within the dataset. In consensus with the recommendations outlined by Bertocchi et al. (2018) and EFSA (2012), three of the five experts noted the absence of animal-based measures; however, they also acknowledged the trade-offs required when attempting to measure animal welfare along with a broader set of sustainability indicators, and the practical alternative provided by routinely collected herd data.

In summary, the expert evaluation identified a number of key factors regarding the proposed welfare variables. Dairy calf mortality and the expansion of the national herd at a sectoral level was identified as a particular welfare challenge impacting the Irish dairy sector at present, in addition to lameness and specifics regarding the age and suitability of animal housing to accommodate expanding herds.

Identifying very low protein or high fat content in milk was confirmed as an acceptable method to indicate potential metabolic risks in dairy cows at a national herd level, in addition to utilising SCC readings as a method to interpret udder health. The provision of appropriate animal bedding was identified as an attribute conducive to heightened welfare levels.

The majority of experts agreed that access to pasture provided an opportunity for animals to express natural behaviours, noting the potential of restricted animal movement to contribute towards the development of pathologies. Issues were raised about investigating antibiotic use on Irish dairy farms; however, the scope of the dataset inhibited the identification of appropriate variables at present. Antibiotic use in agriculture is of particular relevance given the forthcoming EU legislation concerning a move from blanket to selective dry cow therapy. Work is ongoing in terms of collecting data of this nature on farms on a wide scale. This step served as a validation exercise for the variables chosen for this analysis.

\section{Indicator selection}

Following the expert consultation, the proposed variables were extracted from a balanced dataset for the period of 2014-2017 and are presented in Table 1. The dataset contains 250 dairy farms (per year) that returned a full set of data for the 4-yr period.

\section{Normalisation}

As the variables identified measure different concepts and use different scales, it is necessary to normalise and bring the individual variables to a common scale. Normalisation is performed across the 4-yr period using the MIN-MAX approach (OECD, 2008), whereby the lowest value for each variable is subtracted from the value for a given observation 
Table 1: Selected animal welfare variables over balanced NFS dataset, 2014-2017

\begin{tabular}{|c|c|c|c|c|c|c|}
\hline $\begin{array}{l}\text { Variable } \\
(n=1,000)\end{array}$ & Unit & $\begin{array}{c}2014 \\
\text { Average }^{1} \\
\text { (s.d.) }\end{array}$ & $\begin{array}{c}2015 \\
\text { Average }^{1} \\
\text { (s.d.) }\end{array}$ & $\begin{array}{c}2016 \\
\text { Average }^{1} \\
\text { (s.d.) }\end{array}$ & $\begin{array}{c}2017 \\
\text { Average }^{1} \\
\text { (s.d.) }\end{array}$ & $\begin{array}{c}\% \text { Change } \\
2014-2017\end{array}$ \\
\hline \multirow[t]{2}{*}{ Stocking rate } & Livestock units & 2.05 & 2.01 & 2.08 & 2.08 & $+1.5 \%$ \\
\hline & per hectare & $(0.5)$ & $(0.5)$ & $(0.52)$ & $(0.47)$ & \\
\hline \multirow[t]{2}{*}{ Calf mortality rate } & $\%$ & 10 & 11.2 & 11.8 & 10.1 & $+1 \%$ \\
\hline & & $(12.4)$ & $(13.1)$ & $(11.8)$ & (11.3) & \\
\hline \multirow[t]{2}{*}{ Fat-to-protein ratio } & $\%$ & 1.18 & 1.16 & 1.19 & 1.19 & $+0.8 \%$ \\
\hline & & $(0.04)$ & $(0.11)$ & $(0.07)$ & $(0.04)$ & \\
\hline \multirow[t]{2}{*}{ Milk yield } & Litres per cow & 5,214 & 5,489 & 5,361 & 5,422 & $+4 \%$ \\
\hline & & (937) & (907) & (938) & $(1,015)$ & \\
\hline \multirow[t]{2}{*}{ Scc } & '000's cells & 202 & 174 & 168 & 160 & $-21 \%$ \\
\hline & per $\mathrm{mL}$ & (78.25) & (63.63) & $(66.72)$ & $(72.8)$ & \\
\hline Investment in housing & $€$ & 86 & 70 & 67 & 89 & $+3.5 \%$ \\
\hline per cow & & $(245.5)$ & $(211.13)$ & (243.9) & (289) & \\
\hline \multirow[t]{2}{*}{$\%$ with slatted housing } & $\%$ & 92.4 & 92.6 & 92.6 & 92.7 & $+0.3 \%$ \\
\hline & & (17.5) & (17.6) & $(17.6)$ & (16) & \\
\hline \multirow[t]{2}{*}{ Days at grass } & Days per year & 252 & 245 & 247 & 245 & $-3 \%$ \\
\hline & & (22.3) & $(24.7)$ & $(25.1)$ & $(25.8)$ & \\
\hline
\end{tabular}

${ }^{1}$ Reflects weighted average for population. s.d. is given in parentheses. NFS $=$ National Farm Survey, SCC $=$ somatic cell count.

and divided by the range of the dataset for that indicator. Indicators are then scaled from 0 to 100 , with 0 indicating the poorest performance in the sample for the specific variable in any given year and 100 indicating the best performance.

\section{Statistical analysis}

Analysis was conducted on the normalised variables using a multivariate analysis in IBM SPSS Statistics 27.0, with principal component analysis (PCA) utilised as the extraction method. This multivariate statistical procedure allows for trends or patterns within variables to be observed, helping to identify correlations between data points (Eriksson, 2018). Warner et al. (2020) utilised the PCA procedure on routinely collected herd data in the development of a composite welfare index for benchmarking dairy farms in Canada.

The primary component derived from the PCA accounts for the maximum volume of total variance in the observed variables, and the second component generated is correlated with some of the observed variables which are not correlated with the first component, and any subsequent components relaying a progressively smaller amount of variance (O'Shea et al., 2018). Applying the PCA, a five-component solution was derived, which contributed cumulatively to the overall variance by $69 \%$, and which contributed individually to the overall explanation of the variance by more than $10 \%$, in line with the standard practice outlined within the OECD framework (Table 2). Orthogonal rotation was performed to maximise the sum of the squared loadings to better determine how the data correlate with each principal component. An initial test using Promax variation to provide a component correlation matrix determined no value exceeding 0.32 , other than the factor correlating with itself. This indicates that the factors in the analysis were uncorrelated, and therefore an orthogonal rotation was utilised. The rotated pattern factor demonstrated the loadings of variables on each component, where a weighting factor of 0.5 or higher constituted loading on a specific component (Table 3 ).

The first component (PC1) had high loadings of SCC, milk yield and per cow building investment, and the second component had high loadings of days at grass and stocking rate, with fat-to-protein ratio, slatted housing and mortality rate loading on components three, four and five, respectively (Table 3). The Kaiser-Meyer-Olkin measure of sampling adequacy $(\mathrm{KMO}=0.540)$ met the minimum threshold $(>0.50)$ for effective analysis, and the statistical significance of the Bartlett's test of sphericity $(P<0.001)$ indicated that the sample size and the data were adequate for conducting PCA. The weights used for capturing the contribution of each component within the $\mathrm{Cl}$ were determined by the proportion of variance recovered by each component in the total variance, computed from the results in Tables 2 and 3 (Davidescu, 2017). 
Table 2: Empirical results of the principal component analysis

\begin{tabular}{|c|c|c|c|c|c|c|c|c|c|}
\hline \multicolumn{10}{|c|}{ Total variance explained } \\
\hline \multirow[t]{2}{*}{ Component } & \multicolumn{3}{|c|}{ Initial eigenvalues } & \multicolumn{3}{|c|}{ Extraction sums of squared loadings } & \multicolumn{3}{|c|}{ Rotation sums of squared loadings } \\
\hline & Total & $\begin{array}{c}\% \text { of } \\
\text { Variance }\end{array}$ & Cumulative \% & Total & $\begin{array}{c}\% \text { of } \\
\text { Variance }\end{array}$ & Cumulative \% & Total & $\begin{array}{c}\% \text { of } \\
\text { Variance }\end{array}$ & Cumulative $\%$ \\
\hline 1 & 1.42 & 17.78 & 17.78 & 1.42 & 17.78 & 17.78 & 1.25 & 15.66 & 15.66 \\
\hline 2 & 1.09 & 13.66 & 31.44 & 1.09 & 13.66 & 31.44 & 1.12 & 13.97 & 29.63 \\
\hline 3 & 1.04 & 13.03 & 44.47 & 1.04 & 13.03 & 44.47 & 1.10 & 13.78 & 43.41 \\
\hline 4 & 1.00 & 12.43 & 56.90 & 1.00 & 12.43 & 56.90 & 1.03 & 12.89 & 56.30 \\
\hline 5 & 0.96 & 11.96 & 68.86 & 0.96 & 11.96 & 68.86 & 1.01 & 12.56 & 68.86 \\
\hline 6 & 0.94 & 11.72 & 80.58 & & & & & & \\
\hline 7 & 0.86 & 10.77 & 91.36 & & & & & & \\
\hline 8 & 0.69 & 8.65 & 100.00 & & & & & & \\
\hline
\end{tabular}

Extraction method: principal component analysis.

Eight components generated as eight variables examined (somatic cell count (SCC), milk yield, investment in housing per cow, days at grass, stocking rate, fat to protein ratio, \% slatted housing, calf mortality rate). The PCA displays (i) the eigenvalue under the 'Total' column, which is a measure of the variance that is accounted for by the component, (ii) the \% of variance explained by the component, and (iii) the cumulative $\%$ of variance explained.

Table 3: Rotated component matrix with component loadings

\begin{tabular}{lccccc}
\hline & PC1 & PC2 & PC3 & PC4 & PC5 \\
\hline SCC & 0.706 & & & & \\
Milk yield & 0.585 & & & & \\
Investment in housing & 0.611 & & & \\
per cow & & & & & \\
Days at grass & & -0.622 & & & \\
Stocking rate & & 0.756 & & & \\
Fat-to-protein ratio & & & 0.902 & & \\
\% with slatted housing & & & & 0.905 & \\
Calf mortality rate & & & & & 0.990 \\
\hline
\end{tabular}

Extraction method: principal component analysis.

Rotation method: Varimax with Kaiser normalisation.

Rotation converged in six iterations.

$\mathrm{PC}=$ principal component, $\mathrm{SCC}=$ somatic cell count

Squaring the loadings in Table 3 defined the proportion of the total unit variance which is explained by the principal components, while the aggregation was determined by assigning weights to each of the components equal to the proportion of the explained variance in the dataset (OECD, 2008). For this analysis, the variance explained by the first component over the total variance, 1.25 , equates to 0.23 of the total variance, that is, 0.23 $=1.25 /(1.25+1.12+1.10+1.03+1.01)$ and so forth for the remaining components. The $\mathrm{Cl}$, termed the Dairy Cow Welfare Index (DCWI), was thus determined as: $\left(\mathrm{PC} 1{ }^{*} 0.23\right)+(\mathrm{PC} 2$ * $0.20)+(P C 3 * 0.20)+(P C 4 * 0.19)+(P C 5 * 0.18)$
This $\mathrm{Cl}$ was examined across the balanced farm set $(n=250)$ over the 4-yr period 2014-2017, where each farms' annual DCWI score was compared across the time period. Following this, an analysis of DCWI scores across farms which were categorised by their levels of output increase post-quota was undertaken. According to the dataset, the average increase in milk production in 2017 compared with 2014 was 23\%. In order to analyse the impact of this production expansion, farms in the dataset are stratified on the basis of the change in milk production levels over the period. Using the average increase in production (23\%) as a reference point, three strata are identified: non-expanders ( $11 \%$ of the sample), those who did not increase production in 2017 compared with output in 2014 , moderate expanders (43\% of the sample), those who increased production by $23 \%$ or less in 2017 compared with output in 2014, and significant expanders (46\% of the sample), those who increased production by $24 \%$ or more in 2017 compared with 2014 levels.

In addition to analysing dairy cow welfare over time and across farms, it is also interesting to consider how it relates to other aspects of the farm, namely whether any synergies or trade-offs exist between cow welfare and economic or environmental performance of the farm business. In order to interpret this, three established sustainability indicators, two economic (dairy gross margin and income per labour unit) and one environmental ( $\mathrm{kg}$ of GHG per kg of milk produced, measured in line with the Intergovernmental Panel on Climate Change [IPCC] methodology for the determination of emission indicators across farm systems) (Table 4), were extracted from the Teagasc NFS suite of sustainability 
Table 4: Descriptive statistics for selected economic and environmental sustainability indicators

\begin{tabular}{lcccc}
\hline & $\mathbf{2 0 1 4}$ & $\mathbf{2 0 1 5}$ & $\mathbf{2 0 1 6}$ & $\mathbf{2 0 1 7}$ \\
\cline { 2 - 5 } & $\begin{array}{c}\text { Mean } \\
\text { (s.d.) } \\
\mathbf{n}=\mathbf{2 5 0}\end{array}$ & $\begin{array}{c}\text { Mean } \\
(\mathbf{s . d .}) \\
\mathbf{n}=\mathbf{2 5 0}\end{array}$ & $\begin{array}{c}\text { Mean } \\
(\mathbf{s . d .}) \\
\mathbf{n}=\mathbf{2 5 0}\end{array}$ & $\begin{array}{c}\text { Mean } \\
\mathbf{( s . d .} \\
\mathbf{n}=\mathbf{2 5 0}\end{array}$ \\
\hline Dairy gross & 88,991 & 83,334 & 72,504 & 120,724 \\
margin $(€)$ & $(43,095)$ & $(46,126)$ & $(42,971)$ & $(79,353)$ \\
Income per & 54,396 & 52,272 & 44,316 & 71,249 \\
labour unit $(€)$ & $(27,597)$ & $(33,473)$ & $(29,849)$ & $(41,435)$ \\
Kg of GHG & 0.76562 & 0.72383 & 0.7394 & 0.72096 \\
per kg of milk & $(0.12199)$ & $(0.11777)$ & $(0.12494)$ & $(0.11291)$ \\
produced & & & & \\
\hline
\end{tabular}

$\mathrm{GHG}=$ greenhouse gas.

indicators (Buckley et al., 2019) and a correlation analysis undertaken with the DCWI. While this analysis does not attempt to relay a comprehensive interpretation of any tradeoffs existing between dairy cow welfare and overall farm-level sustainability, it may instead provide a cursory overview to any synergies present between welfare levels and different aspects of sustainability. The results of each of these analyses are outlined in the next section.

\section{Results}

Generating a Cl of welfare (DCWI) from the herd-level variables (SCC, dairy calf mortality rate, stocking rate, milk yield, days at grass, fat-to-protein ratio, investment and slatted housing percentage) permitted an efficient method of analysing dairy cow welfare. In this section, we examine the scores of the DCWI (i) over time, (ii) by milk output expansion in 2017 compared with 2014, and (iii) with additional sustainability indicators, across the balanced farm set. Boxplots were utilised to display the data and to facilitate the visualisation of the statistical distribution of the DCWI scores. ${ }^{1}$

\section{Dairy Cow Welfare Index (DCWI) over time}

Annual DCWI scores were compared for each of the 250 farms within the balanced dataset over the 4-yr period, 2014-2017,

${ }^{1}$ Boxplots divide a dataset into quartiles, with the body of the boxplot representing the interquartile range $\left(25^{\text {th }}\right.$ percentile to $75^{\text {th }}$ percentile) with the median dividing the box. Ends of whiskers represent the maximum and minimum values. Outliers are represented by circles beyond the whiskers, with extreme outliers identified by stars.

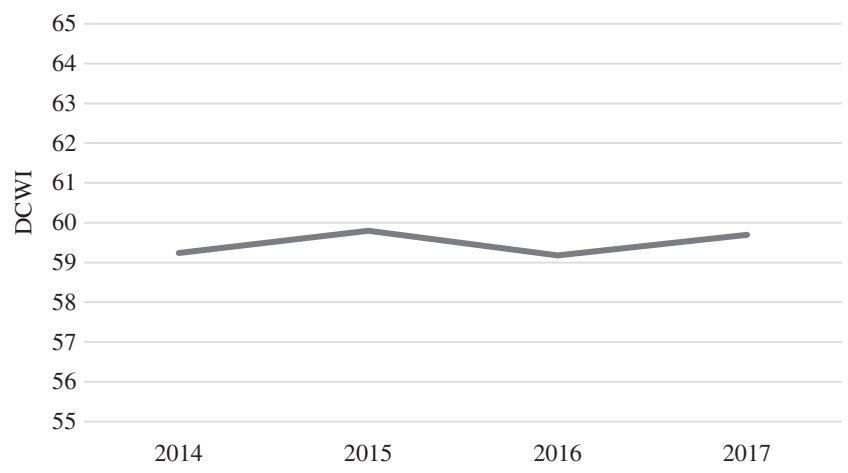

Figure 2. Mean Dairy Cow Welfare Index (DCWI) scores for balanced farm set, 2014-2017.

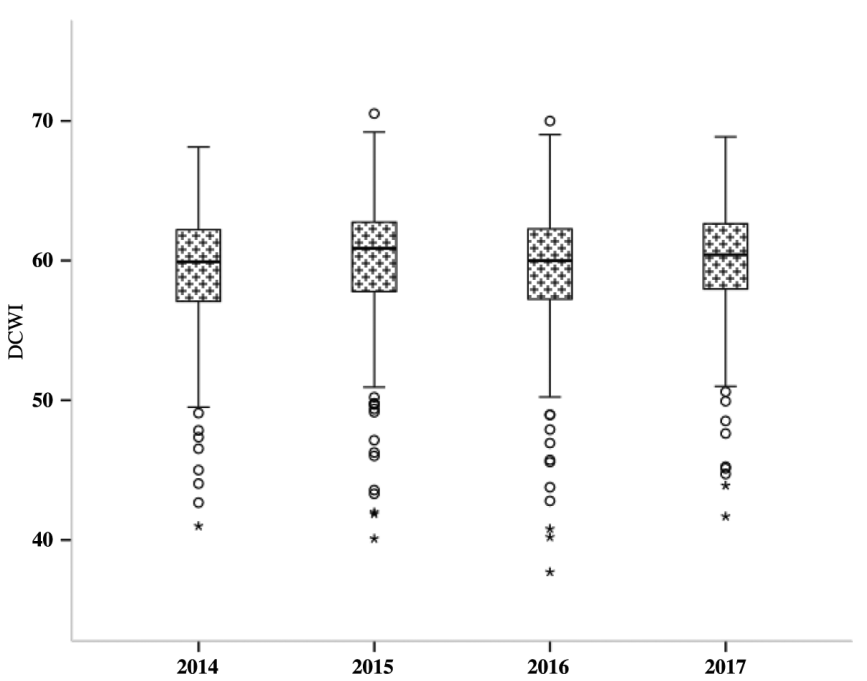

Figure 3. Box and whisker plots of the Dairy Cow Welfare Index (DCWI) for balanced farm set, 2014-2017. See footnote 1 for interpretation of results.

and these scores are visually represented in Figures 2 and 3. Little difference is observed between the DCWI scores over the time period, with marginal fluctuations in average DCWI discernible in Figure 2. The range and distribution of scores have also remained somewhat consistent, as displayed in the boxplots in Figure 3 . This result suggests that welfare standards across the balanced farm set have remained relatively static over the time frame.

\section{DCWI by production levels}

The dairy cow welfare performance (as defined by a selection of relevant variables) of the three cohorts, non-expanders, moderate expanders and significant expanders, as determined 
by their proportion of milk output in 2017 compared with their 2014 output, is visually presented in Figures 4 and 5 . There are a number of interesting points of note. Firstly, the significant expanders are starting from a better cow welfare position in terms of their average performance in comparison to the other groups (Figure 4). This cohort records a wider distribution of their DCWI scores in 2017 compared with their 2014 scores, as observed in the boxplots in Figure 5. The non-expanding group demonstrates a marginal decline in mean DCWI scores in 2017 compared with 2014 scores, the only group to record a decrease, while the moderate expanding cohort of farms

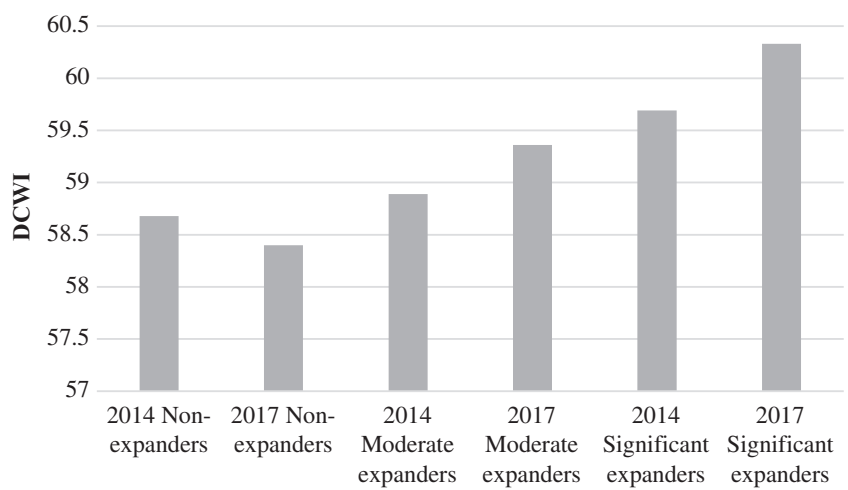

Figure 4. Mean Dairy Cow Welfare Index (DCWI) scores by farm expansion cohort, for the years 2014 and 2017.

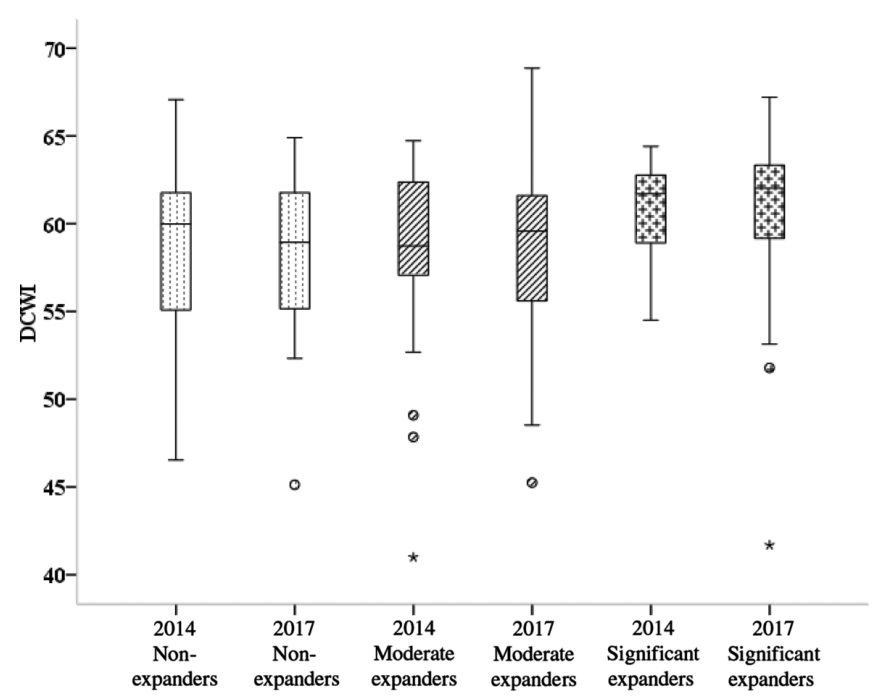

Figure 5. Box and whisker plots of the Dairy Cow Welfare Index (DCWI) by farm expansion cohort, for the years 2014 and 2017. Refer to footnote 1 for interpretation of results. recorded a small improvement in mean DCWI scores and recorded a wider distribution of scores over the time period. Overall, the evidence suggests that as farms have expanded production, the routinely collected variables used within this composite WI have demonstrated improvement.

\section{Trade-off and synergies with additional indicators}

Table 5 demonstrates the results of the correlation analysis between the DCWI, the carbon footprint, measured as $\mathrm{kg}$ of GHG emissions per $\mathrm{kg}$ of milk solids, and the economic indicators, dairy gross margin and income per labour unit. The coefficients reveal that the relationships are significant and positive in relation to economic performance but negative in relation to environmental performance. In other words, as profitability per hectare and per labour unit increases, higher DCWI scores are recorded. Analysis between GHG emissions and DCWI yielded a significant negative correlation over three of the analysed years, indicating that as the GHG emission intensity of milk production declines, an improvement is observed in welfare levels. This may be indicative of higher technical efficiency on such farms. The evidence suggests that win-win strategies are available to farmers and that through efficient management of resources they can increase farm profit, reduce the carbon footprint of each unit of milk produced and improve cow welfare standards.

The relationship is further examined by comparing the economic and environmental performance in 2017 of the top, middle and bottom performing farms from a dairy cow welfare perspective. The positive relationship between economic performance and dairy cow welfare is evident, with the top performers from a cow welfare perspective also delivering the highest margins, which is graphically demonstrated by the boxplot in Figure 6. This finding is further enforced in Figure 7 where farm income per labour unit is also positively correlated with DCWI scoring, reflecting greater welfare standards.

Finally, the relationship with carbon footprint is negative, suggesting that the top performing farms from a dairy cow welfare perspective also have a lower carbon footprint. This is displayed in the boxplots contained in Figure 8, which demonstrates that the top performing DCWI farms record lower levels of GHG emissions per kg of milk produced compared with the other cohorts. This is a win-win result which suggests that farms can deliver higher farm profits, while protecting animal welfare and reducing their GHG emission intensity of production.

\section{Discussion}

This paper presents a number of interesting findings in relation to the impact of milk quota removal on animal welfare performance on dairy farms in Ireland, and provides a 
Table 5: Pearson's correlation coefficients with composite indicator - DCWI and sustainability indicators

\begin{tabular}{|c|c|c|c|c|}
\hline Variables & DCWI 2014 & DCWI 2015 & DCWI 2016 & DCWI 2017 \\
\hline Dairy gross margin $(n=250)$ & 0.118 & $0.200^{1}$ & $0.182^{1}$ & $0.232^{1}$ \\
\hline Income per labour unit $(n=250)$ & $0.139^{2}$ & $0.154^{2}$ & 0.094 & $0.260^{1}$ \\
\hline $\mathrm{Kg}$ of GHG per $\mathrm{kg}$ of milk produced $(n=250)$ & $-0.167^{1}$ & $-0.167^{1}$ & -0.081 & $-0.162^{2}$ \\
\hline
\end{tabular}

${ }^{1}$ Correlation is significant at the 0.01 level (two-tailed).

${ }^{2}$ Correlation is significant at the 0.05 level (two-tailed).

$\mathrm{DCWI}=$ Dairy Cow Welfare Index, GHG = greenhouse gas.

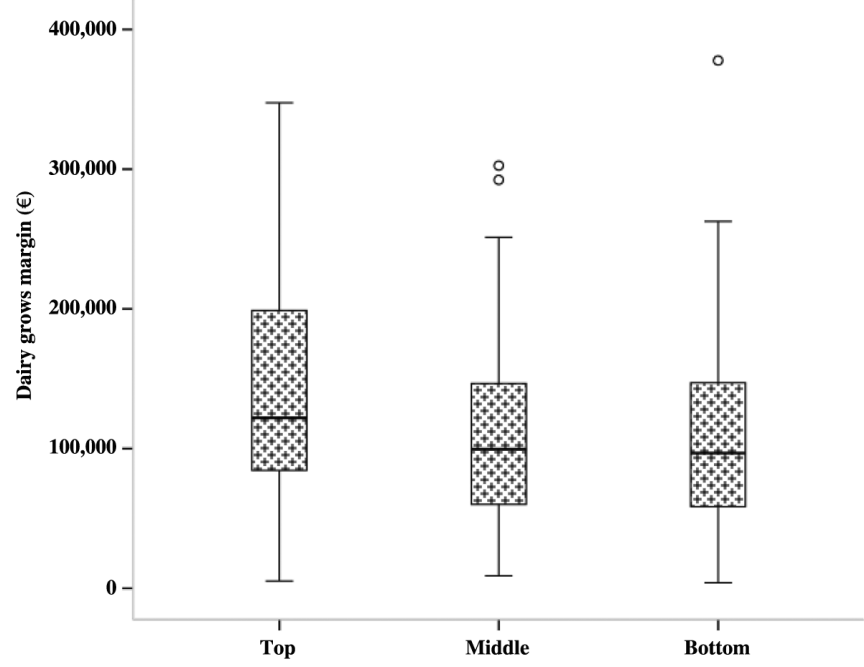

Figure 6. Comparison of top, middle and bottom performing Dairy Cow Welfare Index (DCWI) by dairy gross margin, 2017. Refer to footnote 1 for interpretation of results.

template investigate the effect of other relevant policy reforms. In anticipation of the milk quota abolition in 2015, many dairy farmers in the preceding years sought to expand their herd, with dairy cow numbers increasing annually, from 1,070,800 in 2010 to $1,432,700$ in 2017 (CSO, 2020). This analysis indicates that dairy farms that have significantly expanded production levels since 2014 have recorded improved dairy cow welfare standards on their farms, as supported by the DCWI scores across the different expansion cohorts as seen in Figures 4 and 5 . This finding is in keeping with research by Hansen \& Østerås (2019), which through the development of a welfare index found a positive association between animal welfare and farm expansion. They report that farmers who opted to expand their production were more satisfied with their income and working day, tended to be more optimistic and determined to continue production, in comparison to non-expanding farmers. They hypothesise that this optimistic

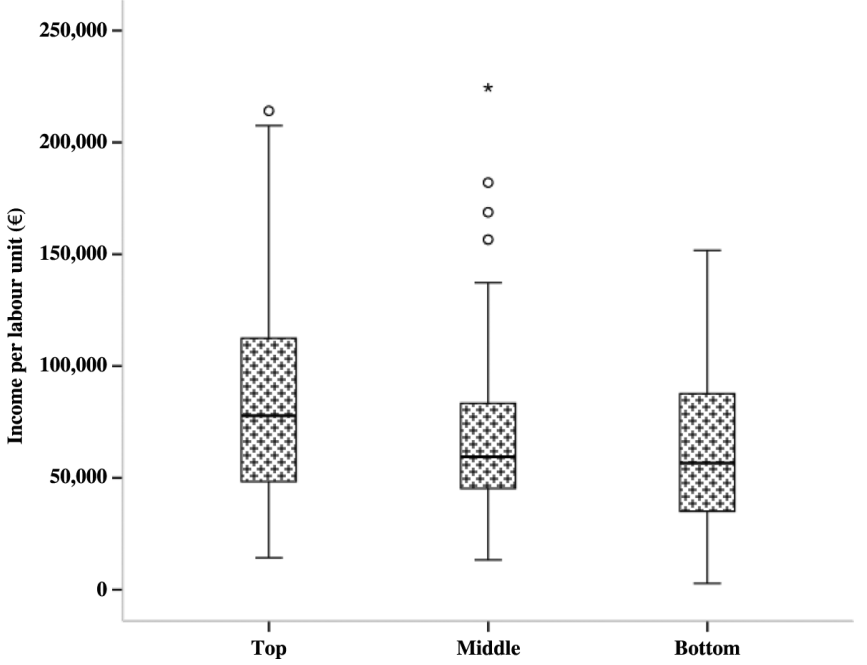

Figure 7. Comparison of top, middle and bottom performing Dairy Cow Welfare Index (DCWI) by farm income per labour unit, 2017. Refer to footnote 1 for interpretation of results.

attitude towards expansion has a positive influence on the quality of stockmanship implemented by the farmer, and with the addition of an equitable work-life balance has a positive impact on animal/herd welfare standards.

Our analysis is also indicative of a significant and positive relationship existing between dairy cow welfare and the economic performance of the farm. The results showed that both in the baseline situation and through time, more profitable farms recorded higher composite welfare scores. This finding is in line with Robichaud et al. (2019), which reported a positive association between good cow welfare levels and improved productivity and longevity, which was reflected in greater economic margins at the farm level. Robichaud et al. (2019) demonstrated that profitability margins per cow were significantly lower in farms with higher incidences of welfare issues, namely knee lesions, while positive associations were established between increased milk yield and reduced 


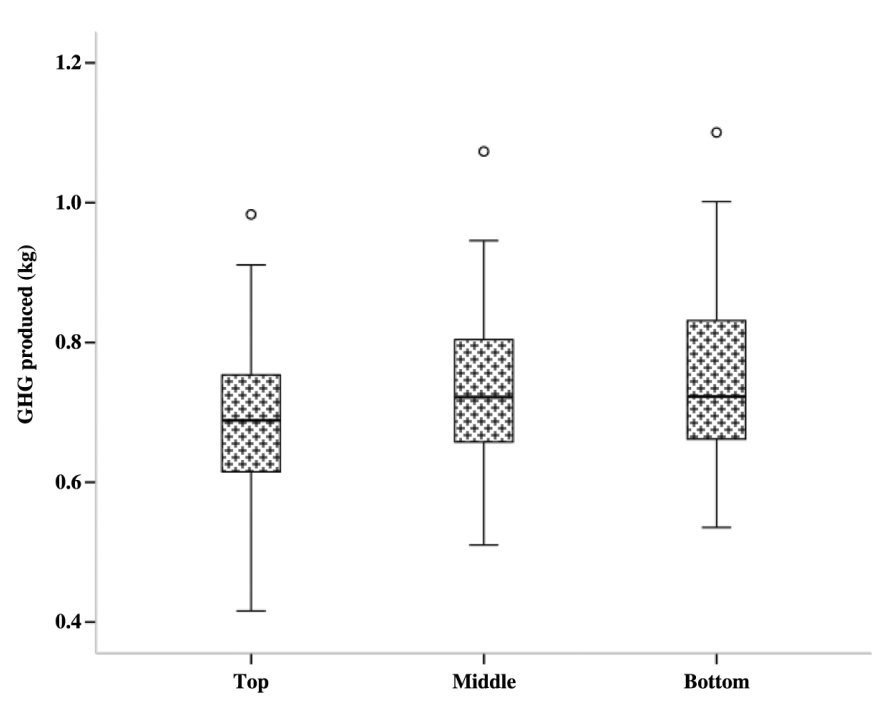

Figure 8. Comparison of top, middle and bottom performing Dairy Cow Welfare Index (DCWI) by kg greenhouse gas (GHG) per kg milk produced, 2017. Refer to footnote 1 for interpretation of results.

prevalence of hoof disorders. This corroborates an earlier study by Barnes et al. (2011) which found that farm economic performance improved with reducing levels of lameness, and stipulated that a clear and positive relationship exists between farm animal welfare and technical efficiency. Hansson et al. (2011) reported that the most efficient dairy farms were characterised by lower incidences of mastitis, which adversely impacts milk yield and carries considerable remediation costs. Consequently, reducing incidences of mastitis can help advance the economic efficiency of dairy farms, alongside improving overall herd health. This speaks to the advantages of applying routinely collected herd data, such as SCC, in the development of composite WIs, which allows for a costeffective comparative analysis between welfare and various aspects of sustainability.

On a further positive note, the analysis revealed that the carbon footprint of milk production was significantly and negatively correlated with animal welfare standards, as DCWI scores were higher across farms which generated lower GHG emissions per kg of milk produced, as evident from the correlation analysis in Table 5 and the boxplots in Figure 8. This suggests that win-win farm-level strategies are available to farmers. Through the adoption of appropriate management practices, technologies and investment in farm facilities, farmers can reduce their carbon footprint, improve farm incomes and enhance animal welfare standards. Further analysis of the data presented in this paper would facilitate the identification and quantification of such win-win strategies. A key policy recommendation arising from this analysis is that farmers should be supported in identifying and applying the appropriate practices and policies for their farms to achieve this optimal outcome. One such practical application includes the adoption of identified technologies under the Teagasc Marginal Abatement Cost Curve (MACC).

Numerous studies exist which assess various aspects of cow welfare on Irish farms, such as the impact of bedding mat types on the welfare of beef cattle (Earley et al., 2017), comparing rubber to concrete pathways on dairy cow hoof health (Boyle et al., 2007) and the effect of space allowance on housed cattle (Keane et al., 2017). These studies provide an in-depth assessment of individual welfare issues, and therefore utilise specifically collected data. This is the first study in an Irish context to utilise routinely collected nationally representative data to address animal welfare.

\section{Limitations on the use of $\mathrm{Cl}$}

It should be noted that the dairy cow WI developed in this paper is only reflective of the variables used in its construction. While each of the herd-level variables which comprise the DCWI (SCC, dairy calf mortality, stocking rate, milk yield, days at grass, fat-to-protein ratio, investment and slatted housing) provide information on different aspects of herd welfare and management, the lack of animal-based measures limits the ability of the DCWI to provide an all-encompassing assessment of welfare. As many of these variables are efficiency and productivity based, such as milk yield, the positive correlations with economic performance may not be surprising. The use of Cls can provide a herd-level overview of animal welfare (Veerasamy et al., 2011), although the approach is not without criticism (Veissier et al., 2009; Sandøe et al., 2019). In particular, the inclusion of certain variables may not be reflective of overall welfare. If data availability was not a limitation, it would be most insightful to expand the variables used to include other measures of welfare such as lameness and antibiotic use.

The EU's Farm to Fork strategy (2020), which is at the heart of the European Green Deal, aims to accelerate the transition to a sustainable food system. It emphasises the need to reduce GHG emissions, protect biodiversity and ensure high animal welfare standards. To achieve these strategic goals, it is imperative that baseline indicators, based on nationally representative, routinely collected data, are established and that the impact of policy reforms on these key sustainability indicators is monitored and evaluated over time. While many farm-level sustainability assessments exist, our literature review suggests that animal welfare has been somewhat neglected. The sustainability framework developed in this paper has shown that it is possible to develop effective animal WIs using a representative farm dataset such as the FADN. Furthermore, it has been demonstrated that animal welfare standards can be tracked through time and embedded in a broader sustainability framework, thus allowing for the assessment of 
synergies and trade-offs with other sustainability indicators. One of the key recommendations arising from this paper is that the FADN should be used to develop a comprehensive assessment of farm-level sustainability including animal welfare. Additional data collection may be required in some countries in order to facilitate this, but as shown for Ireland the richness of the analysis that is possible justifies the activity. Furthermore, the measurement of sustainability will play a key role in the future trajectory of the FADN, as it looks towards its adaptation to the Farm Sustainability Data Network, allowing it to embrace a wider overview of sustainable farming practices across member states.

\section{Conclusion}

This study sought to assess welfare levels on Irish dairy farms through the development of a composite WI, utilising routinely collected herd data. Overall, the results of this study indicate that welfare has remained relatively stable across the 2014-2017 period, and that the recent expansion of the sector has not adversely impacted this composite WI. While societal interest regarding the potential effects of intensive farming on welfare standards is welcome, and enquiry is encouraged, it is positive to observe that in this circumstance, expansion of the Irish dairy industry has not impeded standards of animal welfare as measured with routinely collected herd-level variables. Rather, farms that opted to significantly increase milk output demonstrated improved welfare standards over the study period. Furthermore, no adverse compromises were found between farms recording higher DCWI scores and additional sustainability indicators, with top DCWI performing farms recording improvements across economic and carbon footprint indicators.

The development of the composite WI within this study streamlined various health indicators and WIs into a single holistic welfare measure, with the capacity to compare data with additional measures of sustainability. The scope of these Wls comprising the $\mathrm{Cl}$, estimated at a herd level, has been dictated by the availability of relevant data. Evolving topical issues, such as antibiotic usage, will necessitate additional variables for inclusion within the FADN. While it is acknowledged that animal-based indicators are more insightful than herd-level indicators, which due to data restriction are more limited, we argue that the insights provided by linking animal Wls to a broader set of sustainability indicators for a sample of representative farms for a prolonged period of time have offset many of the limitations. Furthermore, the utilisation of established herdlevel indicators within the $\mathrm{Cl}$ permits time series analysis across each farm in the survey, facilitating the identification of welfare trends across the different expanders. This broadens the remit of these indicators beyond individualistic performance measures, and compared with economic and environmental indicators, can help in attaining future agri-food policy objectives, contributing to a more holistic assessment of farm sustainability.

\section{Acknowledgements}

The authors wish to thank colleagues for their advice, staff involved in the collection and validation of the Teagasc National Farm Survey and the farmers who participated voluntarily in the survey.

\section{References}

Arandia, A., Intxaurrandieta, J., Mangado, J., Santamaría, P., Icaran, C., Lopez, E., Del Hierro, O., Pinto, M., Ruiz, R. and Nafarrate, L. 2011. Incorporating social and environmental indicators in technical and economic advisory programmes in livestock farming. Options Méditerranéennes A 100: 9-15.

Arnott, G., Ferris, C. and O'Connell, N. 2017. Review: welfare of dairy cows in continuously housed and pasture-based production systems. Animal 11: 261-273.

Barnes, A., Rutherford, K., Langford, F. and Haskell, M. 2011. The effect of lameness prevalence on technical efficiency at the dairy farm level: an adjusted data envelopment analysis approach. Journal of Dairy Science 94: 5449-5457.

Battini, M., Vieira, A., Barbieri, S., Ajuda, I., Stilwell, G. and Mattiello, S. 2014. Invited review: animal-based indicators for on-farm welfare assessment for dairy goats. Journal of Dairy Science 97 : 6625-6648.

Bertocchi, L., Fusi, F., Angelucci, A., Bolzoni, L., Pongolini, S., Strano, R.M., Ginestreti, J., Riuzzi, G., Moroni, P. and Lorenzi, V. 2018. Characterization of hazards, welfare promoters and animal-based measures for the welfare assessment of dairy cows: elicitation of expert opinion. Preventive Veterinary Medicine 150: 8-18.

Blokhuis, H., Veissier, I., Miele, M. and Jones, B. 2010. The Welfare Quality ${ }^{\circledR}$ project and beyond: safeguarding farm animal wellbeing. Acta Agriculturae Scand Section A 60: 129-140.

Bonisoli, L., Galdeano-Gómez, E., Piedra-Muñoz, L. and Pérez-Mesa, J.C. 2019. Benchmarking agri-food sustainability certifications: evidences from applying SAFA in the Ecuadorian banana agrisystem. Journal of Cleaner Production 236: 117579.

Boyle, L.A., Mee, J.F. and Kiernan, P.J. 2007. The effect of rubber versus concrete passageways in cubicle housing on claw health and reproduction of pluriparous dairy cows. Applied Animal Behaviour Science 106: 1-12.

Brennan, M., Hennessy, T. and Dillon, E. 2020. Towards a better meaurement of the social sustainability of Irish agriculture. International Journal of Sustainable Development 23: 263-287. 
Brouwer, H., Stegeman, J., Straatsma, J., Hooijer, G. and Van Schaik, G. 2015. The validity of a monitoring system based on routinely collected dairy cattle health data relative to a standardized herd check. Preventive Veterinary Medicine 122: 76-82.

Buckley, C., Donnellan, T., Dillon, E., Hanrahan, K., Moran, B. and Ryan, M. 2019. "Teagasc National Farm Survey 2017 Sustainability Report". Athenry, Co., Galway, Ireland.

CSO. 2020. "Statistical Yearbook of Ireland 2018". CSO, Cork, Ireland. Available online: https://www.cso.ie/en/releasesandpublications/ ep/p-syi/psyi2018/agri/.

Davidescu, A.A. 2017. Measuring the social market economy. A composite index approach for EU countries. Proceedings of the International Conference on Business Excellence. Sciendo, pages 227-240.

de Graaf, S., Ampe, B., Winckler, C., Radeski, M., Mounier, L., Kirchner, M., Haskell, M., Van Eerdenburg, F., Des Roches, A.D.B. and Andreasen, S. 2017. Trained-user opinion about Welfare Quality measures and integrated scoring of dairy cattle welfare. Journal of Dairy Science 100: 6376-6388.

De Vries, M., Bokkers, E., Dijkstra, T., Van Schaik, G. and De Boer, I. 2011. Invited review: associations between variables of routine herd data and dairy cattle welfare indicators. Journal of Dairy Science 94: 3213-3228.

De Vries, M., Bokkers, E., Van Schaik, G., Engel, B., Dijkstra, T. and De Boer, I. 2014. Exploring the value of routinely collected herd data for estimating dairy cattle welfare. Journal of Dairy Science 97: 715-730.

De Vries, M., Engel, B., Den Uijl, I., Van Schaik, G., Dijkstra, T., De Boer, I. and Bokkers, E. 2013. Assessment time of the Welfare Quality ${ }^{\circledR}$ protocol for dairy cattle. Animal Welfare 22: 85-93.

Dillon, E., Hennessy, T., Buckley, C., Donnellan, T., Hanrahan, K., Moran, B. and Ryan, M. 2016. Measuring progress in agricultural sustainability to support policy-making. International Journal of Agricultural Sustainability 14: 31-44.

Dillon, E.J., Hennessy, T. and Hynes, S. 2010. Assessing the sustainability of Irish agriculture. International Journal of Agricultural Sustainability 8: 131-147.

Earley, B., McNamara, J.D., Jerrams, S.J. and O'Riordan, E.G. 2017. Effect of concrete slats, three mat types and out-wintering pads on performance and welfare of finishing beef steers. Acta Veterinaria Scandinavica 59: 34.

Earley, B., Murray, M., Farrell, J. and Nolan, M. 2004. Rearing calves outdoors with and without calf jackets compared with indoor housing on calf health and live-weight performance. Irish Journal of Agricultural and Food Research 43: 59-67.

EFSA. 2012. Scientific Opinion on the use of animal-based measures to assess welfare of dairy cows. EFSA Journal 10: 2554.

Eriksson, L. 2018. "What is principal component analysis (PCA), and how is it used?" Umetrics Suite Blog. Available online: https://blog. umetrics.com/what-is-principal-component-analysis-pca-andhow-it-is-used. 2020 (Accessed 24th March 2020).
European Commission. 2016. Attitudes of Europeans towards animal welfare. Special Eurobarometer 442. ISBN 978-92-79-57116-9. Available online: https://op.europa.eu/en/publication-detail/-/ publication/e31d6cd2-ec16-11e5-8a81-01aa75ed71a1/languageen/format-PDF/source-search (Accessed 10th July 2019).

FAO. 2014. SAFA guidelines: Sustainability assessment of food and agricultural systems. E-ISBN 978-92-5-108597-4 (PDF) Available online: http://www.fao.org/3/i4113e/i4113e.pdf (Accessed 8th December 2019).

FAWC. 2009. "Report on Farm Animal Welfare in Great Britain: Past, Present and Future, Department for Environment". Food \& Rural Affairs, London.

Hansen, B.G. and Østerås, O. 2019. Farmer welfare and animal welfare - exploring the relationship between farmer's occupational well-being and stress, farm expansion and animal welfare. Preventive Veterinary Medicine 170: 104741.

Hansson, H., Szczensa-Rundberg, M. and Nielsen, C. 2011. Which preventive measures against mastitis can increase the technical efficiency of dairy farms? Animal: An International Journal of Animal Bioscience 5: 632-640.

Hanuš, O., Falta, D., Klimešová, M., Samková, E., Říha, J., Chládek, G., Roubal, P., Seydlová, R., Jedelská, R. and Kopecký, J. 2017. Analyse of relationships between some milk indicators of cow energy metabolism and ketosis state. Acta Universitatis Agriculturae et Silviculturae Mendelianae Brunensis 65: 1135-1147.

Jenkins, N.T., Peña, G., Risco, C., Barbosa, C.C., Vieira-Neto, A. and Galvão, K.N. 2015. Utility of inline milk fat and protein ratio to diagnose subclinical ketosis and to assign propylene glycol treatment in lactating dairy cows. The Canadian Veterinary Journal 56: 850.

Keane, M., Mcgee, M., O'Riordan, E., Kelly, A. and Earley, B. 2017. Effect of space allowance and floor type on performance, welfare and physiological measurements of finishing beef heifers. Animal: An International Journal of Animal Bioscience 11: 2285-2294.

Kelly, E., John, F. and Ryan, M. 2017. Long list of indicators. In: "FLINT" Database with project documents (ed.). Available online: https://www.flint-fp7.eu/Database.html (Accessed 11th July 2019).

Lillywhite, R., Keeling, C., Courtney, P., Lampkin, N., Pearce, B., Rayns, F., Reed, M., Schmutz, U., Watson, C. and Williams, A. 2012. Assessing the economic, environmental and social characteristics of UK farming systems. Producing and reproducing farming systems. New modes of organisation for sustainable food systems of tomorrow. 10th European IFSA Symposium, Aarhus, Denmark, July 1-4, 2012, International Farming Systems Association.

Lorenz, I., Earley, B., Gilmore, J., Hogan, I., Kennedy, E. and More, S.J. 2011. Calf health from birth to weaning. III. Housing and management of calf pneumonia. Irish Veterinary Journal 64: 14.

Markert, W. 2017. "Effect of nutrition on milk components". Biomin. net. Available online: https://www2.biomin.net/hu/cikkek/effect-ofnutrition-on-milk-components/. (Accessed 19th November 2019). 
Mee, J. and Boyle, L. 2020. Assessing whether dairy cow welfare is "better" in pasture-based than in confinement-based management systems. New Zealand Veterinary Journal 68: 168-177.

Nardo, M., Saisana, M., Saltelli, A., Tarantola, S., Hoffman, H. and Giovannini, E. 2005. Handbook on constructing composite indicators: methodology and user guide. Organisation for Economic Cooperation and Development (OECD). Statistics Working Paper JT00188147, OECD, France.

Nyman, A.-K., Lindberg, A. and Sandgren, C.H. 2011. Can precollected register data be used to identify dairy herds with good cattle welfare? Acta Veterinaria Scandinavica 53: S8.

Olmos, G., Boyle, L., Hanlon, A., Patton, J., Murphy, J.J. and Mee, J.F. 2009. Hoof disorders, locomotion ability and lying times of cubiclehoused compared to pasture-based dairy cows. Livestock Science 125: 199-207.

O'Shea, R., O'Donoghue, C., Ryan, M. and Breen, J. 2018. Understanding farmers: from adoption to attitudes. 166th Seminar, August 30-31, 2018, Galway, West of Ireland, European Association of Agricultural Economists.

OECD 2008. Handbook on constructing composite indicators, methodology and user guide. Applied Statistics and Econometrics Unit, Joint Research Centre (JRC) of the European Commission, Ispra, Italy.

Ortiz-Pelaez, A., Pritchard, D., Pfeiffer, D., Jones, E., Honeyman, P. and Mawdsley, J. 2008. Calf mortality as a welfare indicator on British cattle farms. The Veterinary Journal 176: 177-181.

Phythian, C.J., Michalopoulou, E. and Duncan, J.S. 2019. Assessing the validity of animal-based indicators of sheep health and welfare: do observers agree? Agriculture 9: 88.

Robichaud, M.V., Rushen, J., De Passillé, A., Vasseur, E., Orsel, K. and Pellerin, D. 2019. Associations between on-farm animal welfare indicators and productivity and profitability on Canadian dairies: I. On freestall farms. Journal of Dairy Science 102: 4341-4351.

Ryan, M., Hennessy, T., Buckley, C., Dillon, E.J., Donnellan, T., Hanrahan, K. and Moran, B. 2016. Developing farm-level sustainability indicators for Ireland using the Teagasc National Farm Survey. Irish Journal of Agricultural and Food Research 55: 112-125.

Sandøe, P., Corr, S.A., Lund, T.B. and Forkman, B. 2019. Aggregating animal welfare indicators: can it be done in a transparent and ethically robust way? Animal Welfare 28: 67-76.

Seppä-Lassila, L., Sarjokari, K., Hovinen, M., Soveri, T. and Norring, M. 2016. Management factors associated with mortality of dairy calves in Finland: a cross sectional study. The Veterinary Journal 216: 164-167.

Sharma, N., Singh, N. and Bhadwal, M. 2011. Relationship of somatic cell count and mastitis: an overview. Asian-Australasian Journal of Animal Sciences 24: 429-438.
Soldi, A., Aparicio Meza, M.J., Guareschi, M., Donati, M. and Insfrán Ortiz, A. 2019. Sustainability assessment of agricultural systems in Paraguay: a comparative study using FAO's SAFA framework. Sustainability 11: 3745.

Talukder, B., Hipel, K.W. and vanLoon, G.W. 2017. Developing composite indicators for agricultural sustainability assessment: effect of normalization and aggregation techniques. Resources 6: 66 .

Teagasc 2016. Feeding the dairy cow. In: TEAGASC (ed.), Teagasc Dairy Manual. Teagasc, Carlow, Ireland. Available online: https:// www.teagasc.ie/publications/2016/teagasc-dairy-manual.php.

Teagasc 2017. Teagasc calf rearing manual, best practice from birth to three months. In: TEAGASC (ed.), Teagasc calf rearing manual. Teagasc, Carlow, Ireland. Available online: https://www.teagasc.ie/ publications/2017/teagasc-calf-rearing-manual.php.

Teagasc 2019. Teagasc National Farm Survey Dairy Enterprise Factsheet 2018. In: TEAGASC (ed.), Teagasc, Athenry, Co. Galway, Ireland. Available online: https://www.teagasc.ie/media/ website/publications/2019/NFS2018DairyFactsheetfinal.pdf.

Van Asselt, E., Van Bussel, L., Van Der Voet, H., Van Der Heijden, G., Tromp, S., Rijgersberg, H., Van Evert, F., Van Wagenberg, C. and Van Der Fels-Klerx, H. 2014. A protocol for evaluating the sustainability of agri-food production systems - a case study on potato production in peri-urban agriculture in The Netherlands. Ecological Indicators 43: 315-321.

Van Calker, K.J., Berentsen, P.B., Giesen, G.W. and Huirne, R.B. 2005. Identifying and ranking attributes that determine sustainability in Dutch dairy farming. Agriculture and Human Values 22: 53-63.

Veerasamy, S., Lakritz, J., Ezeji, T. and Lal, R. 2011. Assessment methods and indicators of animal welfare. Asian Journal of Animal and Veterinary Advances 6: 301-315

Veissier, I., Botreau, R. and Perny, P. 2009. Scoring animal welfare: difficulties and Welfare Quality ${ }^{\circledR}$ solutions. In: "An Overview of the Development of the Welfare Quality Assessment Systems", (ed L. Keeling), School of City and Regional Planning, Cardiff University.

Wang, F., Shao, D., Li, S., Wang, Y., Azarfar, A. and Cao, Z. 2016. Effects of stocking density on behavior, productivity, and comfort indices of lactating dairy cows. Journal of Dairy Science 99: 3709-3717.

Warner, D., Vasseur, E., Villettaz Robichaud, M., Adam, S., Pellerin, D., Lefebvre, D.M. and Lacroix, R. 2020. Development of a benchmarking tool for dairy herd management using routinely collected herd records. Animals 10: 1689.

Winckler, C. 2019. Assessing animal welfare at the farm level: do we care sufficiently about the individual. Animal Welfare 28: 77-82. 